Dear author,

Please note that changes made in the online proofing system will be added to the article before publication but are not reflected in this PDF.

We also ask that this file not be used for submitting corrections. 


\title{
Unified thermodynamic model to calculate COP of diverse sorption heat pump cycles: Adsorption, absorption, resorption, and multistep crystalline reactions
}

\author{
Chaoyi Zhu a,b, Kyle R. Gluesenkamp ${ }^{\text {b,* }}$, Zhiyao Yang ${ }^{c}$, Corey Blackman d,e,f \\ ${ }^{a}$ Building Energy Research Center, Department of Building Science, Tsinghua University, Beijing 100084, China \\ ${ }^{\mathrm{b}}$ Oak Ridge National Laboratory, Building Equipment Research, Energy E' Transportation Science Division, Oak Ridge, TN 37831, USA \\ ${ }^{\mathrm{c}}$ Lyle School of Civil Engineering, Purdue University, West Lafayette, IN 47906, USA \\ d SaltX Technology AB, Västertorpsvägen 135, 12944 Stockholm, Sweden \\ e Dalarna University, Borlänge, Sweden \\ ${ }^{\mathrm{f}}$ School of Business, Society E' Engineering, Mälardalens University, Västerås, Sweden
}

\section{A R T I C L E I N F O}

\section{Article history:}

Received 15 January 2018

Revised 13 November 2018

Accepted 21 December 2018

Available online $\mathrm{xxx}$

\section{Keywords:}

Resorption

Ammonia

Sorption heat pump

Dead thermal mass

Analytical

Heat recovery

\begin{abstract}
A B S T R A C T
A straightforward thermodynamic model is developed in this work to analyze the efficiency limit of diverse sorption systems. A method is presented to quantify the dead thermal mass of heat exchangers Solid and liquid sorbents based on chemisorption or physical adsorption are accommodated. Four possible single-effect configurations are considered: basic absorption or adsorption (separate desorber, absorber, condenser, and evaporator); separate condenser/evaporator (two identical sorbent-containing reactors with a condenser and a separate direct expansion evaporator); combined condenser/evaporator (one salt-containing reactor with a combined condenser/evaporator module); and resorption (two sorbentcontaining reactors, each with a different sorbent). The analytical model was verified against an empirical heat and mass transfer model derived from component experimental results. It was then used to evaluate and determine the optimal design for an ammoniate salt-based solid/gas sorption heat pump for a space heating application. The effects on system performance were evaluated with respect to different working pairs, dead thermal mass factors, and system operating temperatures. The effect of reactor dead mass as well as heat recovery on system performance was also studied for each configuration. Based on the analysis in this work, an ammonia resorption cycle using $\mathrm{LiCl} / \mathrm{NaBr}$ as the working pair was found to be the most suitable single-effect cycle for space heating applications. The maximum cycle heating coefficient of performance for the design conditions was 1.50 with $50 \%$ heat recovery and 1.34 without heat recovery.
\end{abstract}

(c) 2018 Published by Elsevier Ltd.

\footnotetext{
Notice: This manuscript has been authored by UT-Battelle, LLC, under contract DE-AC05-00OR22725 with the US Department of Energy (DOE). The US government retains and the publisher, by accepting the article for publication, acknowledges that the US government retains a nonexclusive, paid-up, irrevocable, worldwide license to publish or reproduce the published form of this manuscript, or allow others to do so, for US government purposes. DOE will provide public access to these results of federally sponsored research in accordance with the DOE Public Access Plan (http://energy.gov/downloads/doe-public-access-plan).

* Corresponding author.

E-mail address: gluesenkampk@ornl.gov (K.R. Gluesenkamp).
}

\section{Introduction}

A natural gas-driven sorption heat pump for space heating applications was proposed and studied by Blackman et al. (2017) with the goal of reducing primary energy consumption and energy cost compared with conventional fuel-fired boilers and furnaces. The heat pump uses ammoniated salt or a salt pair to absorb ammonia refrigerant with three configuration options: the ammoniate adsorption cycle with separate condenser and evaporator (SCE), the ammoniate cycle with combined 


\begin{tabular}{|c|c|}
\hline \multicolumn{2}{|c|}{ Nomenclature } \\
\hline ADS & adsorption system \\
\hline ABS & absorption system \\
\hline COP & coefficient of performance \\
\hline DTMR & dead thermal mass ratio, $\mathrm{kJ}^{-1}$ \\
\hline L & latent heat, $\mathrm{kJ} \mathrm{kg}^{-1}$ \\
\hline Y & loading, $\mathrm{kg}^{-1}$ \\
\hline Q & heat per unit of refrigerant, $\mathrm{kJ} \mathrm{kg}^{-1}$ \\
\hline$T$ & temperature, ${ }^{0} \mathrm{C}$ \\
\hline$m$ & mass, kg \\
\hline$\rho$ & density, $\mathrm{kg} \mathrm{m}^{-3}$ \\
\hline $\mathrm{V}$ & volume, $\mathrm{m}^{3}$ \\
\hline$\Delta H$ & reaction heat, $\mathrm{kJ} \mathrm{kg}^{-1}$ \\
\hline$\Delta T$ & temperature difference, $\mathrm{K}$ \\
\hline$\Delta Y$ & differential loading, $\mathrm{kg}^{-1}$ \\
\hline$C_{p}$ & specific heat, $\mathrm{kJ} \mathrm{kg}^{-1} \mathrm{~K}^{-1}$ \\
\hline$x$ & vapor quality \\
\hline$\varepsilon$ & heat exchange effectiveness \\
\hline$\psi$ & $\begin{array}{l}\text { maximum cooling COP (ratio of latent heats defined } \\
\text { in Table 1) }\end{array}$ \\
\hline HTS & high temperature salt \\
\hline LTS & low temperature salt \\
\hline DTM & dead thermal mass, $\mathrm{kJ} \mathrm{K}^{-1}$ \\
\hline DTMR & dead thermal mass ratio \\
\hline RES & resorption cycle \\
\hline SCE & $\begin{array}{l}\text { ammoniate adsorption cycle with separate con- } \\
\text { denser/evaporator }\end{array}$ \\
\hline CCE & $\begin{array}{l}\text { ammoniate adsorption cycle with combined con- } \\
\text { denser/evaporator }\end{array}$ \\
\hline$\theta_{1}$ & $\begin{array}{l}\text { Parameter associated with the dead thermal mass of } \\
\text { the } \Delta T_{L} \text {-coupled heat exchangers }\end{array}$ \\
\hline$\theta_{2}$ & $\begin{array}{l}\text { Parameter associated with the dead thermal mass of } \\
\text { the } \Delta T_{D} \text {-coupled heat exchangers }\end{array}$ \\
\hline$\varepsilon_{1}$ & $\begin{array}{l}\text { sensible heat recovery fraction for } \Delta T_{L} \text {-coupled heat } \\
\text { exchangers }\end{array}$ \\
\hline$\varepsilon_{2}$ & $\begin{array}{l}\text { sensible heat recovery fraction for } \Delta T_{D} \text {-coupled } \\
\text { heat exchangers }\end{array}$ \\
\hline$\lambda$ & COP approach factor \\
\hline $\mathrm{C} / \mathrm{E}$ & condenser/evaporator \\
\hline \multicolumn{2}{|c|}{ Subscripts } \\
\hline 0 & low temperature heat source \\
\hline 1 & medium temperature heat sink \\
\hline 2 & high temperature heat source \\
\hline$D$ & desorber/difference \\
\hline E & evaporator \\
\hline$L$ & lift \\
\hline des & desorbing \\
\hline cond & condensing \\
\hline comp & ammonia complex \\
\hline$a b s$ & absorbing \\
\hline ads & adsorbing \\
\hline evap & evaporating \\
\hline ht & heating \\
\hline $\mathrm{cl}$ & cooling \\
\hline$i$ & inlet \\
\hline sol & solution \\
\hline $\max$ & maximum \\
\hline $\min$ & minimum \\
\hline ref & refrigerant \\
\hline ret & retained \\
\hline liq & liquid \\
\hline mat & material \\
\hline
\end{tabular}
HTF
HTR high temperature reactor
LTR low temperature reactor
SHX solution heat exchanger

condenser/evaporator (CCE), and the resorption cycle (RES). These configurations are the basic sorption cycle configurations in solid/gas chemisorption heat pump studies (Li et al., 2014; Wang et al., 2014; Wongsuwan et al., 2001). They are the foundation for various advanced cycles. Compared with the more advanced configurations of each type, they require the fewest components to develop a prototype machine (Blackman et al., 2017). To reveal the major characteristics of different cycle configurations, this study focused on these three basic configurations instead of other advanced ones.

The SCE cycle shown in Fig. 1a consists of two identical solid/gas reactors, a condenser, and an evaporator; the CCE cycle shown in Fig. 1b consists of a solid/gas reactor and a combined condenser/evaporator reactor; and the RES cycle shown in Fig. 1c consists of two solid/gas reactors. In the first half-cycle of operation, the heat pump is driven by natural gas where the heat evolving from a natural gas burner is used to desorb ammonia from the reactor to the condenser (SCE and CCE) or the reactor B (RES). The condensation (SCE and CCE) or reaction heat (RES) is used for space heating purposes. In the second half-cycle, the heat of adsorption from the reactor is used for heating purposes while an outdoor fan coil is thermally connected to the evaporator (SCE and CCE) or reactor B (RES) to absorb low-temperature thermal energy from outdoor air. It should be noted that the SCE studied in this work has two identical reactors running out of phase and simultaneously. One reactor is connected to the condenser, and the other is connected to the evaporator every half cycle. The condenser and evaporator run continuously.

Performance analysis and comparison of different configurations using various working pairs are necessary to determine the optimal design for prototype development. Moreover, the effect of dead thermal mass (or DTM, defined here as the sensible heat load [kJ K ${ }^{-1}$ ] due to the cyclic temperature swing of the sorbent, retained refrigerant, heat transfer fluid, and bed material) and different operating conditions should also be considered. In literature, the performance of various sorption cycles was analyzed by modeling and test approaches (Goetz et al., 1997; Zhu et al., 2016). Modeling is the faster and cheaper approach to evaluate a design. Three types of model are usually considered: thermodynamic model, lumped-parameter model, and distributed-parameter model (Pesaran et al., 2016). The thermodynamic model is the fastest and most straightforward model with acceptable error. It is always applied for fast preliminary analysis of sorption systems in many studies.

Thermodynamic studies of absorption cycle started from Carnot heat engine-heat pump model (Herold et al., 2016). Zebbar et al. (2012) applied exergy analysis to find irreversibility of a cycle. Optimizations were made based on that. Herold (1999) provided a zero-order model and compared calculated COP with real machine data. The model showed a more realistic result than reversible model. Xie and Jiang (2015) proposed a new absorption heat pump model based on ideal solution circulation. A temperature lift coefficient was connected to COP to illustrate basic performance of absorption heat pump.

Cacciola and Restuccia (1995) applied thermodynamic model based on first law analysis to calculate and compare the COP and cooling capacity of adsorption cycle with three different working pairs. Zeolite/water was concluded to be the most suitable 
a

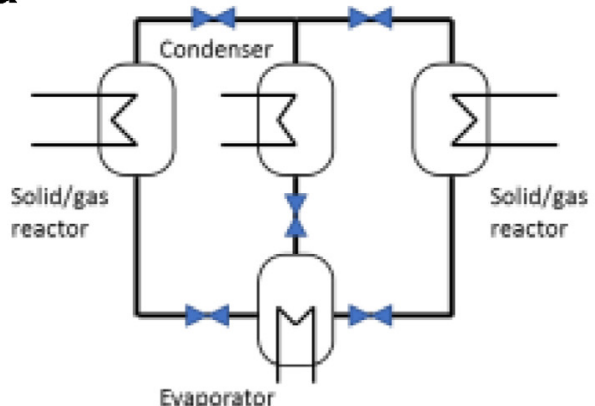

b

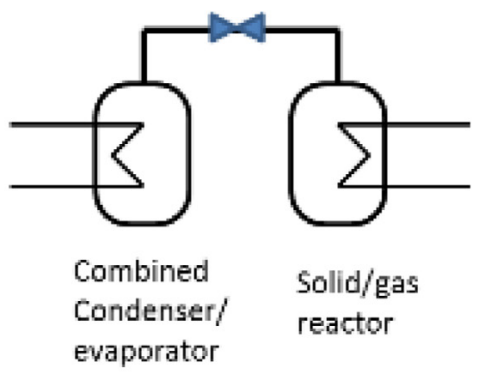

C

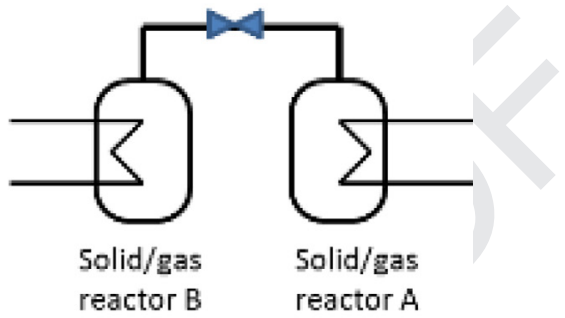

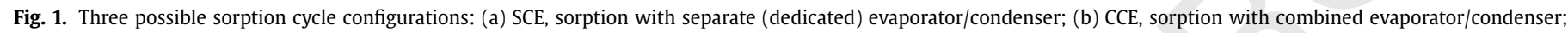
and (c) RES, resorption.

pair for domestic applications in southern Europe. Meunier et al. (1998) defined entropic temperature and introduced equivalent Carnot cycle for thermodynamic modeling of sorption systems. Difference between liquid absorption and solid adsorption technologies was compared by internal entropy production calculation. Pons and Poyelle (1999) applied similar analysis to study two types of vapor recovery cycles. Dead thermal mass was not considered in the model. Douss and Meunier (1988) investigated the effect of operating temperatures on the COP of activated-carbonmethanol adsorption cooling systems with experimental test and a thermodynamic model. The model considered the extra sensible heat requirement of sorbent, refrigerant, and reactor metal under the desorption mode. Freni et al. (2015) developed a thermodynamic model to evaluate adsorption heat pump cycle with combined condenser-evaporator. Dead mass was considered in calculation of desorption and evaporation heat.

Li et al. (2014) provided a uniformed thermodynamic model to calculate performance of solid/gas sorption cycles. Sensible heat consumption was considered as a factor to improve cycle COP. However, the expression of sensible heat was too general that was unable to present key difference between cycles. Neveu and Castaing (1993) used thermodynamic model to compare performance of different solid/gas recovery cycles upgraded from SCE. Dead mass of material and heat transfer fluid were not considered. They also provided a three temperature model from first and second law of thermodynamics (Neveu, \& Castaing, 1996). Sharma and Kumar $(2017,2018)$ applied thermodynamic model in metal hydride based sorption systems to choose suitable metal hydride pair. Material dead mass was considered. The author also considered mass transfer kinetics at different working pressures when selecting working pair candidates.

Present studies established a thermodynamic model for very specific cycles. It is hard to compare key difference between various cycles clearly. For simplification, some studies ignored dead thermal mass effect that would over evaluate the performance of system. Dead thermal mass is influenced by both design ability and inherent salt mass and should be discussed separately to better understand the improvement potential of the system. For fast preliminary analysis of sorption systems with many configuration and working pair options, and to facilitate qualitative comparison among such options, a thermodynamic model that is accurate, computationally efficient, and transparent in its technical meaning is needed.

In this work, a unified thermodynamic model for system COP of sorption cycles was developed to enable rapid performance comparison between, and analysis of, various cycle configurations and working pairs. A simple expression that accommodates ammoniate salt-based chemisorption and many other sorption cycle types was provided. A table was provided to clearly compare key differences between systems: cycle configuration, working pair selection, and system design. Meanwhile, dead mass was considered in a new way that: (a) has separate terms for design-related and inherent mass, (b) is more relevant to cycle performance, and (c) is easier to compute.

\section{Analytical model}

An analytical model is developed in this section to evaluate the heating COP of various sorption cycle configurations. The following assumptions are made to simplify the model:

a. Single effect cycles: Only single effect cycles are considered, in order to reveal the major characteristics of different cycle configurations.

b. Cyclic steady state: The parameters (temperatures and refrigerant loading) at the end of a whole cycle are the same as those at the beginning of the cycle.

c. Mass transfer temperature: The desorption process happens only at $T_{\text {des }}$, the absorption/adsorption process happens only at $T_{a b s} / T_{a d s}$, and the evaporation process happens only at $T_{\text {evap }}$.

d. Thermodynamic equilibrium: Cycle time is not considered; it is assumed that processes reach equilibrium with no mass transfer limitations (solution leaves the desorber and absorber in equilibrium).

e. No heat losses: Losses through pipes and walls are neglected.

f. Sorbent temperature: References are made only to the sorbent bed temperatures (temperatures of external heat transfer fluids are not considered).

g. Lumped capacitance: The sorbent temperature is assumed to be spatially uniform.

\subsection{COP expression for conventional absorption and adsorption cycles}

In this work, the conventional absorption cycle is the basic single stage single effect absorption cycle that consists of a desorber, an absorber, a condenser, an evaporator, and optionally a solution heat exchanger (Herold et al., 2016). The conventional adsorption cycle refers to the basic adsorption cycle with a condenser, an evaporator, and one (or two) adsorption bed(s) as described by Wang et al. (2014). The conventional adsorption cycle is only differs from the SCE in Fig. 1 because the conventional adsorption cycle uses physical adsorption instead of chemisorption.

Analytical models for the cooling or heating COP of absorption and adsorption cycles have been proposed numerous times before; for example in Gluesenkamp (2012) and Freni et al. (2015) The heating COP of a sorption cycle is defined as the ratio between useful heat $Q_{1}$ and driving heat $Q_{2}$, as shown in Eq. (1). It can also 
176

$x_{\text {evap }, i}=\frac{C_{p, \text { ref,liq }} \Delta T_{L}}{L_{\text {evap }}}$

The desorber heat is composed of the latent heat and the sensible heat. The latent heat is the main part of the heat requirement in desorber and is the same for absorption and adsorption cycles. The sensible heat is slightly different between absorption and adsorption cycles. For an absorption cycle, the sensible heating of the solution through the desorber is considered. The desorber heat is shown in Eq. (4). Note that Eq. (4) uses loading $Y$ (i.e., the mass ratio of refrigerant to sorbent) instead of the convention more common for absorption systems (i.e., the mass fraction refrigerant for ammonia/water, or mass fraction sorbent for water/LiBr). The sensible heat depends on the inlet solution mass flow per unit mass flow of refrigerant, the driving temperature difference $\Delta T_{D}=T_{d e s}-T_{a b s}$, the maximum loading in the desorber $Y_{\max }$, the differential loading $\Delta Y=Y_{\max }-Y_{\min }$, and the effectiveness of the solution heat exchanger $\varepsilon_{S H X}$. The solution temperature difference can be calculated from $\Delta T_{\text {sol }}=\left(1-\varepsilon_{S H X}\right) \Delta T_{D}$, and the mass flow of solution per unit mass flow of refrigerant is $\frac{\left(1+Y_{\max }\right)}{\Delta Y}$. Then, by combining Eqs. (1)-(4), the heating COP for absorption cycle can be expressed as Eq. (5). Note that the use of $Y_{\max }$ is due to assumption c, which states that all desorption occurs at $T_{d e s}$. Thus all refrigerant in the sorbent at the end of sorption (associated with $Y_{\max }$ ) must be sensibly heated in the transition from sorption to desorption.

$Q_{D}=L_{d e s}+C_{p, s o l}\left(1-\varepsilon_{S H X}\right) \Delta T_{D} \frac{\left(1+Y_{\max }\right)}{\Delta Y}$

$C O P_{h t}=1+\frac{L_{\text {evap }}-C_{p, \text { ref,liq }} \Delta T_{L}}{L_{\text {des }}+C_{p, s o l}\left(1-\varepsilon_{S H X}\right) \Delta T_{D} \frac{\left(1+Y_{\text {max }}\right)}{\Delta Y}}$
For an adsorption cycle, the desorption and adsorption processes occur separately in the same reactor. The sensible heat should include heating of the adsorbent, retained refrigerant, heat transfer fluid (HTF), bed material, and other possible "dead thermal masses" in the adsorber/desorber. Gluesenkamp (2012) defined a term dead thermal mass ratio (DTMR) to capture the relative size of these dead thermal masses. In this framework, the dead thermal mass (DTM), defined in Eq. (6a) is the aggregate of all thermal masses that must be heated and cooled each cycle. The DTMR is defined in Eq. (6b) as a dimensionless ratio of sensible heat to latent heat per cycle, including heat transfer fluid, heat exchanger materials, and the sensible heat of the sorbent and refrigerant. The sensible heat per cycle is DTM [ $\left.\mathrm{kJ} \mathrm{K}^{-1}\right]$ multiplied by $\Delta \mathrm{T}_{\mathrm{D}}[\mathrm{K}]$, and the latent heat per cycle is the latent heat of desorption [kJ] per cycle. Note that the product of $\Delta Y$ and $m_{a d s}$ give the mass of refrigerant transferred per half-cycle (also referred to as the active mass).

Using the DTMR, we can derive the heating COP for a typical adsorption cycle without heat recovery in Eq. (7). A more detailed expression that accounts for heat recovery is included in the work of Gluesenkamp (2012). Note that DTM is strictly a function of the geometry of the physical sorbent heat exchanger. As will be shown later, the impact of DTM on the cycle efficiency is mediated by DTMR, which also includes operating parameters (temperatures and working fluid properties).

$D T M=\rho_{H T F} V_{H T F} C_{p, H T F}+\rho_{\text {mat }} V_{\text {mat }} C_{p, \text { mat }}+m_{a d s}\left(C_{p, a d s}+Y_{\text {max }} C_{p, r e f, \text { liq }}\right)$

$D T M R=\frac{\Delta T_{D} D T M}{\Delta Y m_{\text {ads }} L_{d e s}}$

$C O P_{h t}=1+\frac{L_{\text {evap }}-C_{p, r e f, l i q} \Delta T_{L}}{L_{\text {des }}(1+D T M R)}$

2.2. COP expression for ammoniate sorption with separate dedicated condenser and evaporator

In this section, the heating COP of an ammoniate sorption cycle with separate dedicated condenser and evaporator is derived. The expression for evaporator heat is the same compared with the conventional adsorption cycle. The desorber heat consists of both reaction heat and sensible heat. The reaction heat $\Delta H_{\text {des }}$ depends on the working pair and reaction process. The sensible heat is like that of the conventional adsorption cycle except that ammoniate composite instead of refrigerant is retained in the desorber. The DTMR and heating COP for ammoniate sorption cycle are shown in Eqs. (8) and (9).

$$
\begin{aligned}
D T M R= & \frac{\Delta T_{D}}{\Delta Y m_{a d s} \Delta H_{\text {des }}}\left(\rho_{H T F} V_{H T F} C_{p, H T F}+\rho_{\text {mat }} V_{\text {mat }} C_{p, \text { mat }}\right. \\
& \left.+\left(1+Y_{\text {max }}\right) m_{a d s} C_{p, \text { comp }}\right) \\
C O P_{h t}=1 & +\frac{L_{\text {evap }}-C_{p, \text { ref,liq }} \Delta T_{L}}{\Delta H_{\text {des }}(1+D T M R)}
\end{aligned}
$$

\subsection{COP expression for cycle with combined condenser/evaporator}

The combined condenser/evaporator configuration can be used for both physical adsorption (such as water/silica gel) and chemical sorption (such as ammonia/ammoniated salts). The distinguishing characteristic of the CCE cycle is that a single chamber is used as the condenser in one half cycle and as the evaporator in the other half-cycle. This leads to two main differences compared with the conventional cycle. Firstly, the refrigerant will not go through an expansion process; therefore, the vapor fraction of the refrigerant at the beginning of evaporation is zero. Secondly, the dead thermal masses in the combined condenser/evaporator are cooled from $T_{\text {cond }}$ to $T_{\text {evap }}$ during the evaporation process, which reduces the evaporator heat and undermines the COP. The DTMR for evaporator and evaporator heat is shown in Eqs. (10) and (11). The $m_{\text {ref.ret }}$ is the retained mass of refrigerant at the end of the condensing process.

$$
\begin{aligned}
D T M R_{E}= & \frac{\Delta T_{L}}{\Delta Y m_{\text {ads }} L_{\text {evap }}}\left(\rho_{H T F, E} V_{H T F, E} C_{p, H T F, E}+\rho_{\text {mat }, E} V_{\text {mat }, E} C_{p, \text { mat }, E}\right. \\
& \left.+m_{\text {ref,ret }} C_{p, \text { ref }, \text { liq }}\right)
\end{aligned}
$$


Table 1

Expressions for characters in different systems.

\begin{tabular}{lllll}
\hline System configuration & Abbr. & $\psi$ & $\theta_{1}$ & $\theta_{2}$ \\
\hline Absorption cycle & ABS & $\frac{L_{\text {evap }}}{L_{\text {des }}}$ & $\frac{C_{p, \text { ref,liq }} \Delta T_{L}}{L_{\text {eva }}}$ & $C_{p, \text { sol }} \Delta T_{D} \frac{\left(1+Y_{\text {min }}\right)}{\Delta Y L_{\text {des }}}$ \\
Adsorption cycle & ADS & $\frac{L_{\text {evap }}}{L_{\text {des }}}$ & $\frac{C_{p, \text { ref,liq }} \Delta T_{L}}{L_{\text {eva }}}$ & DTMR \\
Separate condenser/ evaporator cycle & SCE & $\frac{L_{\text {evap }}}{\Delta H_{\text {des }}}$ & $\frac{C_{p, \text { ref,liq }} \Delta T_{L}}{L_{\text {eva }}}$ & DTMR \\
Combined condenser/ evaporator cycle & CCE & $\frac{L_{\text {evap }}}{\Delta H_{\text {des }}}$ & DTMR & DTMR \\
Resorption cycle & RES & $\frac{\Delta R_{\text {LTS }}}{\Delta H_{H T S}}$ & DTMR & DTMR \\
\hline
\end{tabular}

$Q_{E}=L_{\text {evap }}\left(1-D T M R_{E}\right)$

The desorber DTMR in Eq. (6) for conventional adsorption desorber or in Eq. (8) for ammoniate sorption desorber can be used for COP calculation for the combined condenser/evaporator cycle depending on the sorption process. The heating COP for this combined condenser/evaporator cycle is shown in Eq. (12).

$C O P_{h t}=1+\frac{L_{\text {evap }}\left(1-D T M R_{E}\right)}{L_{\text {des }}\left(1+D T M R_{D}\right)}$

280

$$
\begin{aligned}
& D T M R_{H T R}=\frac{\Delta T_{D}}{\Delta Y_{H T S} m_{H T S} \Delta H_{H T S}}\left(\rho_{H T F, H T R} V_{H T F, H T R} C_{p, H T F, H T R}\right. \\
& \left.+\rho_{\text {mat }, H T R} V_{\text {mat }, H T R} C_{p, \text { mat }, H T R}+\left(1+Y_{\text {max }, H T S}\right) m_{H T S} C_{p, H T S, \text { comp }}\right)
\end{aligned}
$$

$$
C O P_{h t}=1+\frac{\Delta H_{L T S}\left(1-D T M R_{L T R}\right)}{\Delta H_{H T S}\left(1+D T M R_{H T R}\right)}
$$

$$
C O P_{h t}=1+\frac{\sum_{i=1}^{n} \frac{\Delta Y_{\text {LTS. }} \Delta H_{\text {LTSS.i }}}{\Delta Y_{\text {LTS }}}\left(1-D T M R_{L T R}\right)}{\sum_{j=1}^{m} \frac{\Delta Y_{\text {HTS.j. }} \Delta H_{\text {HTS.j }}}{\Delta Y_{\text {HTS }}}\left(1+D T M R_{H T R}\right)}
$$

\subsection{Unified expression for all configuration types}

Based on Eqs. (1), (5), (7), (9), (12), and (15) or (16), the universal expression of heating COP for a sorption system is shown in Eq. (17), and the meaning of each term is explained in Table 1. The systems related to ammoniate sorption are SCE, CCE, and RES.

$\mathrm{COP}_{h t}=1+\psi \frac{1-\theta_{1}}{1+\theta_{2}}$

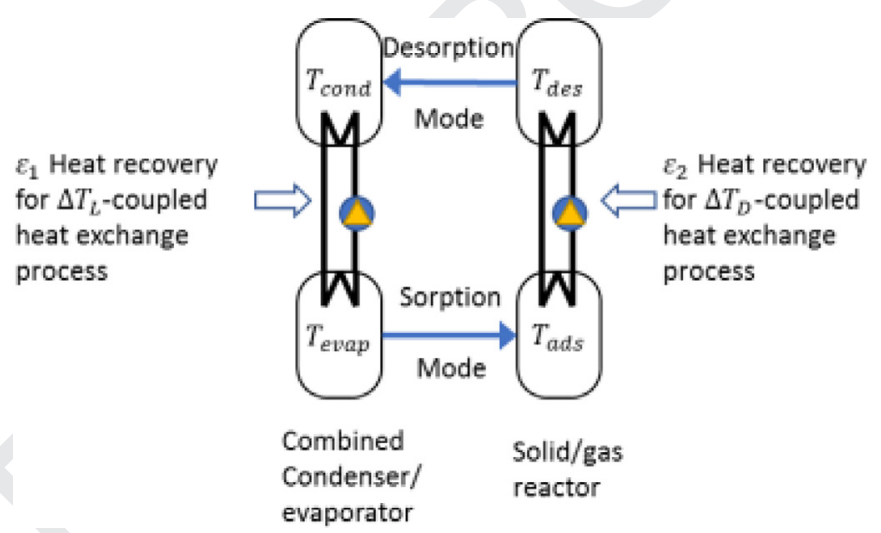

Fig. 2. System with heat recovery (using a combined condenser/evaporator as an example).

Any one of these configurations is generally capable of incorporating heat recovery, according to the following considerations.

Heat recovery can be accomplished from the $\Delta T_{L}$-coupled heat exchange process, where at least two discrete heat exchangers are used for heat exchange with $T_{\text {cond }}$ and $T_{\text {evap }}$. The fraction of sensible heat recovered from the $\Delta T_{L}$-coupled heat exchangers is denoted here as $\varepsilon_{1}$, as shown in Fig. 2.

Similarly, any one of these configurations is capable of incorporating heat recovery from the $\Delta T_{D}$-coupled heat exchange process, when at least two discrete heat exchangers are used for heat exchange with $T_{d e s}$ and $T_{a d s}$. The fraction of sensible heat recovered from the $\Delta T_{D}$-coupled heat exchangers is denoted here as $\varepsilon_{2}$, as also shown in Fig. 2.

To accommodate heat recovery, Eq. (17), which assumes no heat recovery, can be modified as shown in Eq. (18). Note that heat recovery $\varepsilon_{1}$ is always zero for cycles not considering dead thermal mass in the low temperature heat source-driven reactor.

Note that the effectivenesses $\varepsilon_{1}$ and $\varepsilon_{2}$ act only on the sensible heat. This can be observed by inspection of Eq. (18) and the definition of $\theta_{1}$ and $\theta_{2}$, by evaluating these expressions with values of $\varepsilon_{1}=\varepsilon_{2}=0$ and $\varepsilon_{1}=\varepsilon_{2}=1$. In other words, in this work, heat recovery effectiveness is the fraction of sensible heat that can be recovered. A scheme that recovers latent heat as well (such as the well-known generator-absorber exchange or GAX cycle) would have an effectiveness greater than one since latent heat is recovered in addition to sensible heat.

$\mathrm{COP}_{h t}=1+\psi \frac{1-\left(1-\varepsilon_{1}\right) \theta_{1}}{1+\left(1-\varepsilon_{2}\right) \theta_{2}}$

In Eqs. (17) and (18), the ratio expression after $\psi$ shows the gap between real cooling COP and maximum single effect cooling COP because of the effects of dead thermal mass and other penalties. We name this ratio as the COP approach factor $(\lambda)$, as shown in Eq. (19). A higher $\lambda$ means the COP is closer to maximum COP. 
Table 2

Comparison of DTM $\mathrm{Design}_{\text {and }}$ DTM $\mathrm{M}_{\text {inherent }}$ for each configuration and heat exchanger type.

\begin{tabular}{|c|c|c|}
\hline Type $^{a}$ & $D T M_{\text {design }}$ & DTM $M_{\text {inherent }}$ \\
\hline ABS & 0 & $\left(1-\varepsilon_{S H X}\right)\left(1+Y_{\max }\right) m_{a b s} C_{p, s o l}$ \\
\hline ADS & $\rho_{H T F} V_{H T F} C_{p, H T F}+\rho_{\text {mat }} V_{\text {mat }} C_{p, \text { mat }}$ & $m_{a d s}\left(C_{p, a d s}+Y_{\max } C_{p, r e f, l i q}\right)$ \\
\hline SCE & $\rho_{\text {HTF }} V_{H T F} C_{p, H T F}+\rho_{\text {mat }} V_{\text {mat }} C_{p, \text { mat }}$ & $\left(1+Y_{\max }\right) m_{a d s} C_{p, \text { comp }}$ \\
\hline CCE-Evaporator & $\rho_{H T F, E} V_{H T F, E} C_{p, H T F, E}+\rho_{\text {mat }, E} V_{\text {mat }, E} C_{p, \text { mat }, E}$ & $m_{\text {ref,ret }} C_{p, r e f, l i q}$ \\
\hline CCE-Desorber & $\rho_{H T F, D} V_{H T F, D} C_{p, H T F, D}+\rho_{\text {mat }, D} V_{\text {mat }, D} C_{p, \text { mat }, D}$ & $\left(1+Y_{\max }\right) m_{a d s} C_{p, \text { comp }}$ \\
\hline RES-LTR & $\rho_{H T F, L T R} V_{H T F, L T R} C_{p, H T F, L T R}+\rho_{\text {mat }, L T R} V_{\text {mat }, L T R} C_{p, \text { mat }, L T R}$ & $\left(1+Y_{\max , L T S}\right) m_{L T S} C_{p, L T S, \text { comp }}$ \\
\hline RES-HTR & $\rho_{H T F, H T R} V_{H T F, H T R} C_{p, H T F, H T R}+\rho_{\text {mat }, H T R} V_{\text {mat }, H T R} C_{p, \text { mat }, H T R}$ & $\left(1+Y_{\max , H T S}\right) m_{H T S} C_{p, H T S, \text { comp }}$ \\
\hline
\end{tabular}

a $\mathrm{ABS}=$ absorption cycle; $\mathrm{ADS}=$ adsorption cycle; $\mathrm{DTM}=$ dead thermal mass; $\mathrm{SCE}=$ separate condenser and evaporator; $\mathrm{CCE}=$ combined condenser/evaporator; $\mathrm{RES}=$ resorption cycle; $\mathrm{LTR}=$ low temperature reactor; HTR = high temperature reactor.

When $\lambda$ equals 1 , the real COP is equal to maximum COP.

$\lambda=\frac{1-\left(1-\varepsilon_{1}\right) \theta_{1}}{1+\left(1-\varepsilon_{2}\right) \theta_{2}}$

Combining this definition with Eq. (18) yields Eq. (20).

$C O P_{h t}=1+\psi \lambda$

In Eqs. (6), (8), (10), (13), and (14), the DTM can be defined as the sum of two parts as shown in Eq. (21). For each heat exchanger type, the definitions of DTM design and DTM inherent change slightly, as shown in Table 2 .

$D T M=D T M_{\text {design }}+D T M_{\text {inherent }}$

The DTM design represents the dead thermal mass of HTF and heat exchanger material. Clearly, this has a very strong dependence on reactor dimensions and design. This is generally the primary source of dead thermal mass, and it can be optimized.

The DTM inherent represents the dead thermal mass of salt and refrigerant. These depend primarily on inherent thermophysical properties. However, it is also important to note that, since the quantity of refrigerant may vary with cycle time and other operating conditions, the DTM inherent does have some slight dependence on operating conditions.

For reactor design, the ideal condition is when DTM design equals zero. With a given working pair, working condition, mass of salt, and mass of refrigerant vapor, a better design usually means a lower DTM design and higher performance.

\section{Model verification and validation}

In this section, we focus on the cooling COP because it is the most widely available in existing literature. The heating COP model is considered verified and validated at the same time because of its connection with cooling COP (as expressed in Eq. (1)).

Most published literature on experimental and modeled performance of sorption systems does not include sufficient information to determine the dead thermal mass of the system in question. A few examples were found. For all of these examples that included sufficient information about dead thermal mass, we performed validation against experimental studies and verification with numerical studies, as described in Sections 3.1 and 3.2.

\subsection{Conventional absorption and adsorption cycles}

For conventional absorption and adsorption cycles, the COP expression used in this work is identical to those used by two previous references, as follows.

The COP expression for a conventional absorption heat pump was verified previously by Gluesenkamp (2012) by comparing the analytical model of cooling COP with the result from a numerical model for single effect absorption chiller in Herold et al. (2016). The analytical model COP was 0.735 , and the COP from the detailed numerical model was 0.720 .
Table 3

Parameters used in coefficient of performance verification ${ }^{\mathrm{a}}$.

\begin{tabular}{|c|c|c|c|}
\hline & Value & & Unit \\
\hline$T_{d e s, ~ H T S}$ & 150 & & ${ }^{\circ} \mathrm{C}$ \\
\hline$T_{a d s, H T S}$ & 30 & & ${ }^{\circ} \mathrm{C}$ \\
\hline$T_{\text {des, LTS }}$ & 5 & & ${ }^{\circ} \mathrm{C}$ \\
\hline$T_{a d s, ~ L T S}$ & 30 & & ${ }^{\circ} \mathrm{C}$ \\
\hline$\Delta T_{D}$ & 120 & & $\mathrm{~K}$ \\
\hline$\Delta T_{L}$ & 25 & & $\mathrm{~K}$ \\
\hline Properties of reactors & HTS & LTS & \\
\hline Mass of salt & 2.57 & 2.125 & $\mathrm{~kg}$ \\
\hline Mass of expanded graphite & 1.385 & 1.145 & $\mathrm{~kg}$ \\
\hline Mass of heat exchange material & 15 & 12 & $\mathrm{~kg}$ \\
\hline Volume of HTF & 9 & 7.8 & $\mathrm{~L}$ \\
\hline Density of HTF & $N / A^{b}$ & $N / A^{b}$ & $\mathrm{~kg} \mathrm{~L}^{-1}$ \\
\hline Specific heat of HTF & $\mathrm{N} / \mathrm{A}^{\mathrm{b}}$ & $\mathrm{N} / \mathrm{A}^{\mathrm{b}}$ & $\mathrm{kJ} \mathrm{kg}^{-1} \mathrm{~K}^{-1}$ \\
\hline Specific heat of salt ${ }^{b}$ & 0.6 & 0.44 & $\mathrm{~kJ} \mathrm{~kg}^{-1} \mathrm{~K}^{-1}$ \\
\hline Specific heat of expanded graphite ${ }^{c}$ & 0.61 & 0.61 & $\mathrm{~kJ} \mathrm{~kg}^{-1} \mathrm{~K}^{-1}$ \\
\hline Specific heat of liquid refrigerant ${ }^{c}$ & 4.59 & 4.59 & $\mathrm{~kJ} \mathrm{~kg}^{-1} \mathrm{~K}^{-1}$ \\
\hline Specific heat of stainless steel ${ }^{c}$ & 0.46 & 0.46 & $\mathrm{~kJ} \mathrm{~kg}^{-1} \mathrm{~K}^{-1}$ \\
\hline Maximum loading & 0.486 & 0.710 & $\mathrm{~kg}^{-1}$ salt \\
\hline Differential loading & 0.432 & - & $\mathrm{kg}^{-1}$ salt \\
\hline Reaction heat ${ }^{d}$ & 2789 & 2250 & $\mathrm{~kJ} \mathrm{~kg}^{-1}$ ref \\
\hline
\end{tabular}

Notes: $\mathrm{HTS}=$ high temperature salt; $\mathrm{LTS}=$ low temperature salt; $\mathrm{HTF}=$ heat transfer fluid.

a Source: Lepinasse et al. (1994). Modelling and experimental investigation of a new type of thermochemical transformer based on the coupling of two solid-gas reactions. Chemical Engineering and Processing: Process Intensification, 33 (3), 125-134.

b Values were not provided in the original source.

c Specific heat comes from: Bao et al. (2011). Working pairs for resorption refrigerator. Applied Thermal Engineering, 31 (14), 3015-3021.

d Reaction heat comes from: Li et al. (2014). Progress in the development of solid-gas sorption refrigeration thermodynamic cycle driven by low-grade thermal energy. Progress in Energy and Combustion Science, 40, $1-58$. The COP expression for a conventional adsorption heat pump 361 was verified previously by Qian et al. (2013). The cooling COP an- 362 alytical model was compared with experiment data of 170 test 363 points for a synthetic zeolite-based adsorption system. The differ- 364 ence was within $\mathrm{a} \pm 10 \%$ range.

\subsection{Resorption cycle with two reactors and two adsorbents}

Two sources, both using ammoniate sorption, were used to confirm the analytical model for the resorption cycle with two reactors and two adsorbents. The sensible heat of both reactors was considered.

The analytical model in this work was verified against the numerical model for the resorption cycle using two solid-gas reactors studied by Lepinasse et al. (1994). $\mathrm{MnCl}_{2}$ and $\mathrm{BaCl}_{2}$ were used as HTS and LTS, respectively. Lepinasse et al. (1994) validated their numerical model against experimental results. The input parameters for the model calculation are shown in Table 3. 62 3

64


Table 4

Comparison of coefficient of performance (COP) calculation result between analytical and numerical models.

\begin{tabular}{lll}
\hline & With dead thermal mass of adsorbent & With dead thermal mass of adsorbent + heat exchange material \\
\hline$D T M R_{H T R}$ & 0.31 & 0.58 \\
$D T M R_{L T R}$ & 0.09 & 0.14 \\
COP $_{\text {analytical }}$ (this work) $^{a}$ & 0.56 & 0.44 \\
OP $_{\text {numerical }}$ & 0.54 & 0.45 \\
\hline
\end{tabular}

Note: DTMR = dead thermal mass ratio; LTR = low temperature reactor; HTR = high temperature reactor.

a Lepinasse et al. (1994). Modelling and experimental investigation of a new type of thermochemical transformer based on the coupling of two solid-gas reactions. Chemical Engineering and Processing: Process Intensification 33 (3), 125-134.

Table 5

Parameters used in coefficient of performance validation ${ }^{\mathrm{a}}$.

\begin{tabular}{llllll}
\hline & \multicolumn{3}{l}{ Working pair } & & \\
\cline { 2 - 6 } & $\mathrm{MnCl}_{2} / \mathrm{NH}_{4} \mathrm{Cl}$ & $\mathrm{MnCl}_{2} / \mathrm{NaBr}$ & & & \\
\hline$\Delta T_{D}$ & $\mathrm{~K}$ & 65 & & 120 \\
$\Delta T_{L}$ & $\mathrm{~K}$ & 30 & $\mathrm{LTS}$ & $\mathrm{HTS}$ & $\mathrm{LTS}$ \\
& & $\mathrm{HTS}$ & 55.35 & 55.5 & 34.59 \\
Mass of salt & $\mathrm{g}$ & 100.09 & 27.51 & 29.88 & 18.63 \\
Mass of expanded graphite & $\mathrm{g}$ & 50.06 & 582.89 & 732.42 & 515.98 \\
Mass of heat exchange material & $\mathrm{g}$ & 774.38 & 1.55 & 0.6 & 0.505 \\
Specific heat of salt & $\mathrm{kJ} \mathrm{kg}^{-1} \mathrm{~K}^{-1}$ & 0.61 & 0.61 & 0.61 & 0.61 \\
Specific heat of expanded graphite & $\mathrm{kJ} \mathrm{kg}^{-1} \mathrm{~K}^{-1}$ & 0.61 & 4.59 & 4.59 & 4.59 \\
Specific heat of refrigerant & $\mathrm{kJ} \mathrm{kg}^{-1} \mathrm{~K}^{-1}$ & 4.59 & 0.46 & 0.46 & 0.46 \\
Specific heat of stainless steel & $\mathrm{kJ} \mathrm{kg}^{-1} \mathrm{~K}^{-1}$ & 0.46 & 0.812 & 0.518 & 0.781 \\
Maximum loading & $\mathrm{kg}^{-1}$ salt & 0.486 & - & 0.507 & - \\
Differential loading & $\mathrm{kg}^{-1}$ salt & 0.432 & 1630 & 2924 & 1790 \\
Reaction heat & $\mathrm{kJ} \mathrm{kg}^{-1}$ ref & 2740 & & \\
\hline
\end{tabular}

Notes: HTS = high temperature salt; LTS = low temperature salt.

a Source: Xu et al., (2011). Resorption system with simultaneous heat and cold production. International Journal of Refrigeration 34 (5), 1262-1267.

Table 6

Comparison of coefficient of performance (COP) between analytical model and experiment result.

\begin{tabular}{lll}
\hline & \multicolumn{2}{l}{ Working pair } \\
\cline { 2 - 3 } & $\mathrm{MnCl}_{2} / \mathrm{NH}_{4} \mathrm{Cl}$ & $\mathrm{MnCl}_{2} / \mathrm{NaBr}$ \\
\hline$D T M R_{H T R}$ & 0.368 & 0.759 \\
$D T M R_{\text {LTR }}$ & 0.246 & 0.232 \\
COP $_{\text {analytical }}$ (this work) & 0.33 & 0.27 \\
COP $_{\text {experiment }}{ }^{a}$ & 0.35 & 0.31 \\
\hline
\end{tabular}

Notes: DTMR = dead thermal mass ratio; $\mathrm{LTR}=$ low temperature reactor; $\mathrm{HTR}=$ high temperature reactor.

a Source: Xu et al., (2011). Resorption system with simultaneous heat and cold production. International Journal of Refrigeration 34 (5), 1262-1267.
Lepinasse et al. (1994) used their numerical model to calculate the COP under three different dead thermal mass scenarios: considering DTM of adsorbent only; considering DTM of adsorbent and material; and considering DTM of adsorbent, material, and HTF. The authors did not provide information about the type of HTF used. Therefore, we cannot verify our result against theirs for the case of including DTM of HTF. We used the analytical model from this work to calculate COP assuming DTM of HTF is zero, and the comparison between our result and literature's result is shown in Table 4. The COP calculated by two models had less than \pm 0.02 difference. The analytical model in this work showed good agreement with the classical numerical model and used less calculation time.

Secondly, the analytical model in this work was validated by experimental results from two classical experiments of the resorption cycle. One used $\mathrm{MnCl} 2$ as HTS and $\mathrm{NH} 4 \mathrm{Cl}$ as LTS (Xu et al., 2011), and the other used the same HTS with $\mathrm{NaBr}$ as LTS (Bao et al., 2011). The parameters provided by these studies are listed in Table 5 as calculation input. The result is shown in Table 6. The COP difference between calculation and experiment result is less than 0.04. Therefore, the analytical model demonstrates a good 397 agreement with experimental result.

In this section, the analytical model of cooling COP was verified against numerical model results in the literature and was validated against experimental results in the literature. The maximum cooling COP deviation was less than 0.04. Based on Eq. (1), the heating COP model was also verified and validated, and the relative difference in COP would be lower for heating COP.

\section{Using the model to choose the best cycle for an example application}

In this section, the verified analytical model is used to evaluate and determine the optimal cycle configuration and working pairs for a sorption heat pump used in a space heating application. In this example application, the assumed design target of the sorption heat pump for space heating is to produce $10 \mathrm{~kW}$ of $50^{\circ} \mathrm{C}$ hot water at an ambient of $-10^{\circ} \mathrm{C}$ and with a heat source temperature of $250^{\circ} \mathrm{C}$.

\subsection{Selection of working pair}

To select optimal working pairs for the sorption heat pump, equilibrium lines of potential ammoniates are illustrated on a Clapeyron diagram in Fig. 3. The operating temperatures and pressures are also shown in Fig. 3. The choices of LTS shown in the blue area on Fig. 3 are constrained by the ambient temperature. However, the operating pressure should also be considered, as in practice high vacuum conditions (i.e., low ammonia vapor pressures) usually lead to a limited mass transfer rate and subsequently low heating power. Therefore, the LTSs operating at higher pressure (lighter blue area) are better options than those that operate at low pressure (darker blue area). The choices of HTS are shown in the red area of Fig. 3. In the case of the HTS selection, the con- 


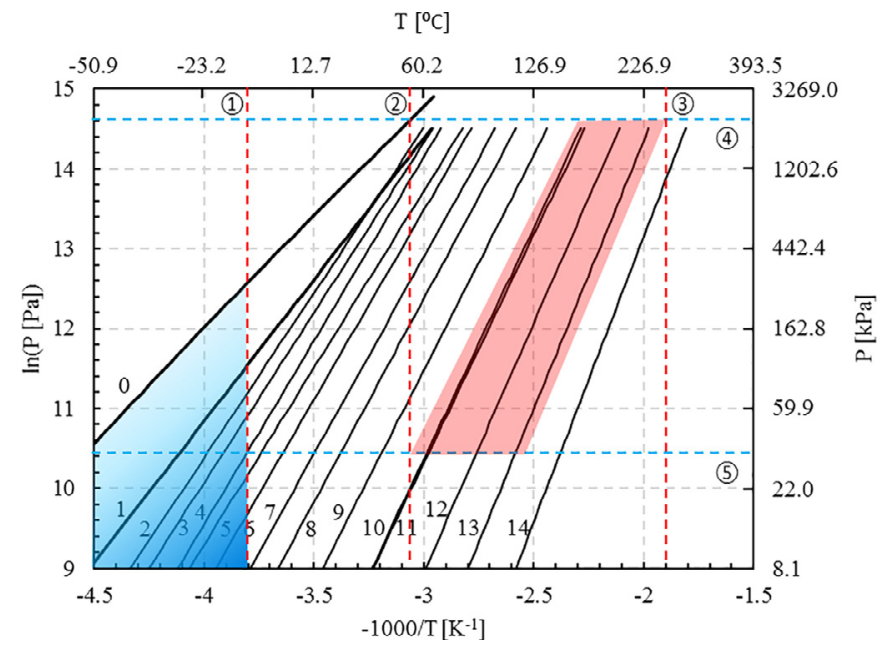

Fig. 3. The Clapeyron diagram of different reaction steps. [Notes: $0-\mathrm{NH}_{3} ; 1-$ $\mathrm{NH}_{4} \mathrm{Cl}(3 / 0) ; 2-\mathrm{PbCl}_{2}$ (8/3.25); 3-NaBr (5.25/0); 4- $\mathrm{BaCl}_{2}$ (8/0); 5- $\mathrm{LiCl}(4 / 3) ; 6-\mathrm{PbCl}_{2}$ (3.25/2); 7- $\mathrm{CaCl}_{2}$ (8/4); 8- $\mathrm{CaCl}_{2}(4 / 2) ; 9-\mathrm{LiCl}(3 / 2) ; 10-\mathrm{LiCl}(2 / 1) ; 11-\mathrm{MnCl}_{2}(6 / 2)$; $12-\mathrm{LiCl}(1 / 0) ; 13-\mathrm{MgCl}_{2}$ (6/2); $14-\mathrm{NiCl}_{2}$ (6/2). (1)-ambient temperature; (2)-hot water supply temperature; (3)-heat source temperature; (4)-assumed highest feasible pressure; (5)-assumed lowest feasible pressure. Reaction enthalpy and entropy come from Li et al. (2014)].

Table 7

Heating coefficient of performance and sorbent mass for different working pairs.

\begin{tabular}{|c|c|c|c|c|}
\hline \multicolumn{2}{|l|}{ Resorption } & \multirow[t]{2}{*}{$\psi$} & \multicolumn{2}{|c|}{ Sorbent mass $\left[\mathrm{g} \mathrm{kJ}^{-1}\right]$} \\
\hline HTS & LTS & & HTS & LTS \\
\hline $\mathrm{MnCl}_{2}(6 / 2)$ & $\mathrm{NH}_{4} \mathrm{Cl}(3 / 0)$ & 1.62 & 0.66 & 0.60 \\
\hline $\mathrm{LiCl}(3 / 0)$ & $\mathrm{NH}_{4} \mathrm{Cl}(3 / 0)$ & 1.61 & 0.29 & 0.60 \\
\hline $\mathrm{MgCl}_{2}(6 / 2)$ & $\mathrm{NH}_{4} \mathrm{Cl}(3 / 0)$ & 1.53 & 0.43 & 0.60 \\
\hline $\mathrm{MnCl}_{2}(6 / 2)$ & $\mathrm{PbCl}_{2}(8 / 3.25)$ & 1.72 & 0.66 & 1.71 \\
\hline $\mathrm{LiCl}(3 / 0)$ & $\mathrm{PbCl}_{2}(8 / 3.25)$ & 1.71 & 0.29 & 1.71 \\
\hline $\mathrm{MgCl}_{2}(6 / 2)$ & $\mathrm{PbCl}_{2}(8 / 3.25)$ & 1.62 & 0.43 & 1.71 \\
\hline $\mathrm{MnCl}_{2}(6 / 2)$ & $\mathrm{NaBr}(5.25 / 0)$ & 1.75 & 0.66 & 0.55 \\
\hline $\mathrm{LiCl}(3 / 0)$ & $\mathrm{NaBr}(5.25 / 0)$ & 1.73 & 0.29 & 0.55 \\
\hline $\mathrm{MgCl}_{2}(6 / 2)$ & $\mathrm{NaBr}(5.25 / 0)$ & 1.64 & 0.43 & 0.55 \\
\hline $\mathrm{MnCl}_{2}(6 / 2)$ & $\mathrm{BaCl}_{2}(8 / 0)$ & 1.81 & 0.66 & 0.68 \\
\hline $\mathrm{LiCl}(3 / 0)$ & $\mathrm{BaCl}_{2}(8 / 0)$ & 1.79 & 0.29 & 0.68 \\
\hline $\mathrm{MgCl}_{2}(6 / 2)$ & $\mathrm{BaCl}_{2}(8 / 0)$ & 1.69 & 0.43 & 0.68 \\
\hline Sorption & & $\psi$ & \multicolumn{2}{|c|}{ Sorbent mass $\left[\mathrm{g} \mathrm{kJ}^{-1}\right]$} \\
\hline $\mathrm{MnCl}_{2}(6 / 2)$ & & 1.43 & \multicolumn{2}{|l|}{0.66} \\
\hline $\mathrm{LiCl}(3 / 0)$ & & 1.42 & \multicolumn{2}{|l|}{0.29} \\
\hline $\mathrm{MgCl}_{2}(6 / 2)$ & & 1.37 & \multicolumn{2}{|l|}{0.43} \\
\hline
\end{tabular}

Notes: $\mathrm{HTS}=$ high temperature salt; $\mathrm{LTS}=$ low temperature salt.

straints are imposed by the hot water supply and heat source temperatures as well as the working pressure.

For the resorption cycle, comprising two reactors with two adsorbents, the potential LTSs include $\mathrm{NH}_{4} \mathrm{Cl}, \mathrm{PbCl}_{2}, \mathrm{NaBr}$, and $\mathrm{BaCl}_{2}$, whereas the potential HTSs include $\mathrm{LiCl}, \mathrm{MnCl}_{2}$, and $\mathrm{MgCl}_{2}$. In considering sorption cycles with only one adsorbent, the candidates include $\mathrm{LiCl}, \mathrm{MnCl}_{2}$, and $\mathrm{MgCl}_{2}$. Based on Eqs. (7,) (9), (12), and (15), the maximum cooling COP (assuming DTMR $=0$ ), regardless of system configuration and dead thermal mass factors, has been calculated and is shown in Table 7 . The term $\psi$ is the ratio of reaction heats, which also corresponds to the maximum single effect cooling COP. The reaction heat $\psi$ discussed here is defined as the amount of heat rejected or absorbed in the chemical reaction with one unit of ammonia vapor adsorbed by or desorbed from the salt sorbent; it is defined for each system type in Table 1.

With the selected working pairs, the resorption cycles in general demonstrate better maximum COP than sorption cycles demonstrate because the reaction heat of LTS is larger than the ammonia latent heat. The working pair of $\mathrm{MnCl}_{2} / \mathrm{BaCl}_{2}$ has the highest $\psi$ (see Table 7); however, the extremely low operating pressure of $\mathrm{BaCl}_{2}$ as the LTS is a major concern because of low power density. In practice, lower power density tends toward a larger (and thus more expensive) system for a given heating capacity. $\mathrm{NaBr}$ and $\mathrm{PbCl}_{2}$ as LTS have similar $\psi$ and higher operating pressure, but $\mathrm{PbCl}_{2}$ has much lower energy density (Li et al., 2013) manifested as an elevated sorbent mass per unit of reaction heat in one desorption or sorption mode ( $\mathrm{g} \mathrm{kJ}$ ). As shown in Table 7, using $\mathrm{MnCl}_{2}$ or $\mathrm{LiCl}$ as the HTS leads to higher COPs compared with using $\mathrm{MgCl}_{2}$ as the HTS. However, again $\mathrm{LiCl}$ has higher energy density and lower sorbent mass per unit of reaction heat than that of $\mathrm{MnCl}_{2}$.

The best candidates for the resorption cycle are $\mathrm{NaBr}(5.25 / 0)$ as LTS and $\mathrm{LiCl}(3 / 0)$ as HTS because this working pair has demonstrated a good $\psi$ and a low sorbent mass per unit of refrigerant latent heat. Correspondingly, in the case of the SCE and CCE sorption cycles, $\mathrm{LiCl}$ as HTS is considered the best option.

\subsection{Selection of system configuration}

The aim of this section is to find a suitable system configuration to realize a higher COP more easily. This is determined by both $\psi$ (defined in Section 4.1) and the COP approach factor $\lambda$ (defined in Eq. (20)).

We defined DTM as the sum of design-related DTM design and fluid-related $D T M_{\text {inherent }}$ (see Eq. (21)). In Fig. 5, the effect of DTM design on $\theta_{1}, \theta_{2}$, and $\lambda$ for each working pair and configuration is illustrated. Generally systems are easier to build with a higher allowance for $D T M_{\text {design }}$, but the performance is limited; with low DTM design and higher theoretical performance, realizing the design becomes increasingly challenging. We plot the figure applying $\mathrm{LiCl} / \mathrm{NaBr}$ for RES cycle and $\mathrm{LiCl}$ for SCE and CCE cycles to illustrate the main trends. We also plot two of the most commonly used working pairs for RES as reference of how much the DTM design and $\lambda$ can be in common practice; oil is assumed to be the HTF with density of $890\left(\mathrm{~kg} \mathrm{~m}^{-3}\right)$ and specific heat of $1.8\left(\mathrm{~kJ} \mathrm{~kg}^{-1} \mathrm{~K}^{-1}\right)$.

To make the DTM design for different applications comparable, we use the ratio of $D T M_{\text {design }}$ divided by active mass of refrigerant $\left(\Delta Y m_{a d s}\right)$ to represent DTM design level of one application. The active mass of refrigerant means the total mass of refrigerant vapor adsorbed for heating in sorption mode. For simplicity, we assume that DTM design of LTR equals DTM design of HTR for the RES configuration and that $D T M_{\text {design }}$ of the salt reactor is twice the $D T M_{\text {design }}$ of the C/E for the CCE cycle. These assumptions are deemed reasonable for the authors' current application but might be different for other exchanger design and heat transfer fluid flow network design. With the present model the system designer can change relation between DTM $M_{\text {design }}$ of HTR, LTR, and C/E according to their own design level and draw a similar figure for comparison.

According to Fig. 4, the SCE and CCE cycles using $\mathrm{LiCl}$ salt have the same $\theta_{1}, \theta_{2}$, and $\lambda$ when $D T M_{\text {design }}=0$. As the $D T M_{\text {design }}$ level increases, the CCE has a lower $\lambda$ than SCE cycle. The $\lambda$ difference between the CCE and SCE cycles increases because the CCE cycle has to consider the DTM design of C/E HTF and materials. Comparing $\lambda$ of SCE using $\mathrm{LiCl}$ and RES using $\mathrm{LiCl} / \mathrm{NaBr}$, the $\lambda$ of the RES cycle is higher than that of the SCE cycle when the DTM design level is low; the $\lambda$ of the SCE cycle is higher than that of the RES cycle when the DTM design level is high. Given reactor design properties like mass of HTF and mass of material, the DTM design level can be calculated, and the performance of different cycles can be compared easily. For example, the DTM design levels of design calculated according to Table 8 for SCE, CCE, and RES configurations are shown as black " $X$ " mark points in Fig. 5. The SCE cycle has slightly better $\lambda$ than the RES cycle. However, the difference of $\lambda$ is small so that the RES cycle using $\mathrm{LiCl} / \mathrm{NaBr}$ may still have higher
446 447 448 449 450 451 452 453 454 455 456 457 458 459 460 461 462 


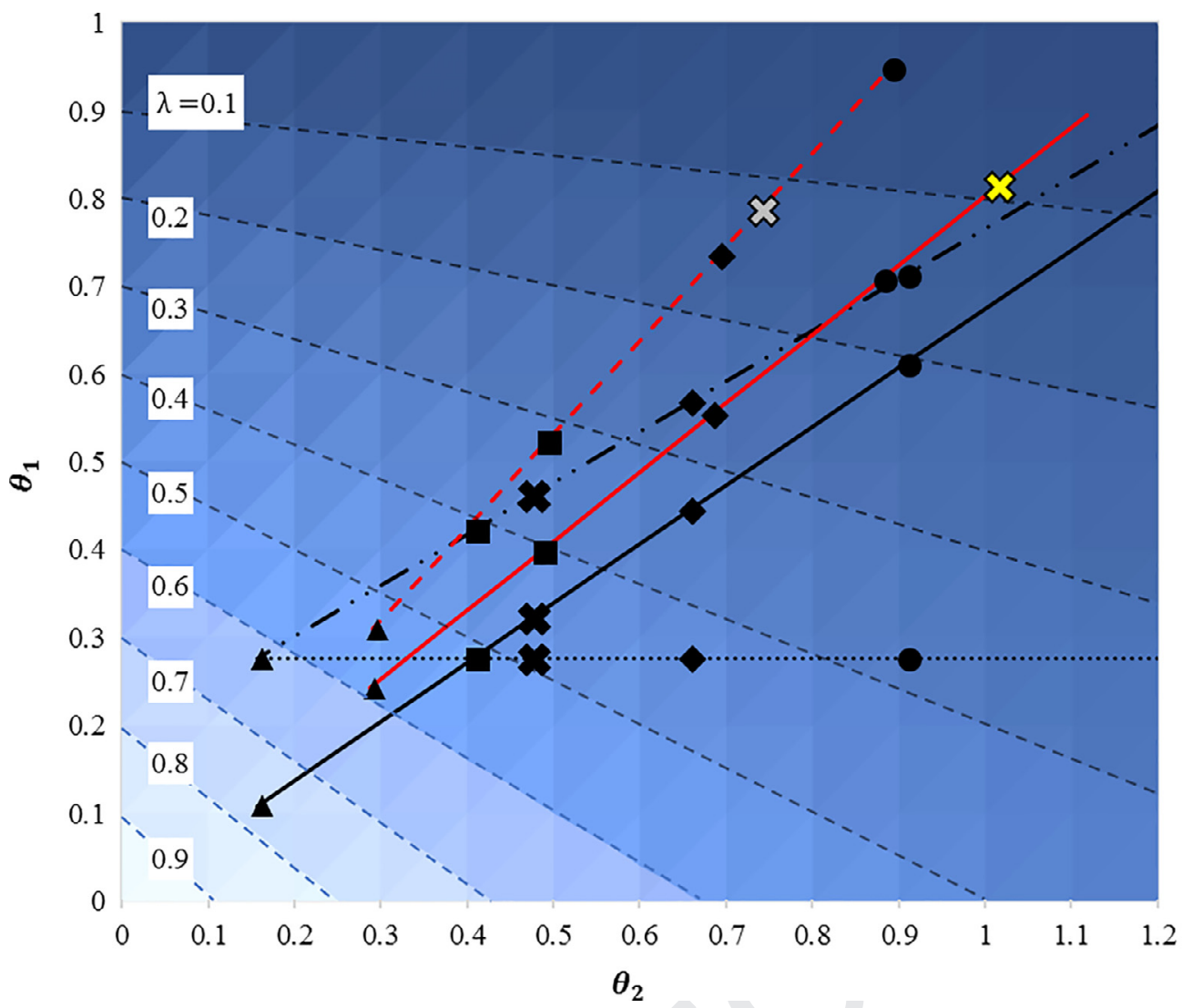

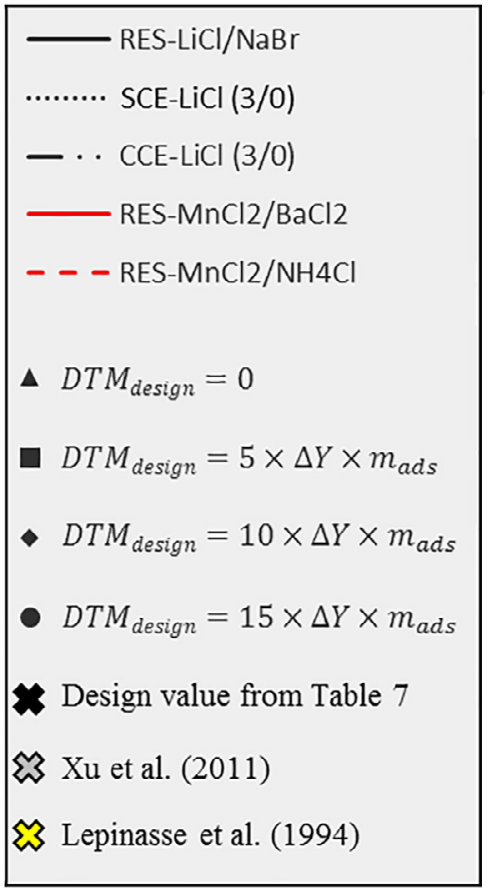

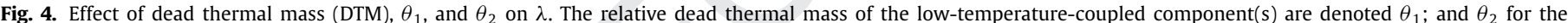
high-temperature coupled components. These combine to form the penalty factor $\lambda$ as defined in Eq. (19).

Table 8

Comparison of different system configurations.

\begin{tabular}{lllllll}
\hline Configuration & Working pair & $\psi$ & $\theta_{1}$ & $\theta_{2}$ & $\mathrm{COP}_{h t}, \varepsilon_{1}=\varepsilon_{2}=0$ & $\mathrm{COP}_{h t}, \varepsilon_{1}=\varepsilon_{2}=0.5$ \\
\hline SCE & $\mathrm{LiCl}(3 / 0)$ & 0.42 & 0.27 & 0.48 & 1.21 & 1.29 \\
$\mathrm{CCE}$ & $\mathrm{LiCl}(3 / 0)$ & 0.42 & 0.44 & 0.48 & 1.16 & 1.27 \\
$\mathrm{RES}$ & $\mathrm{LiCl} / \mathrm{NaBr}$ & 0.73 & 0.32 & 0.48 & 1.34 & 1.50
\end{tabular}

Notes: $\mathrm{COP}=$ coefficient of performance; $\mathrm{SCE}=$ separate condenser and evaporator; $\mathrm{CCE}=$ combined condenser/evaporator; RES = resorption cycle.

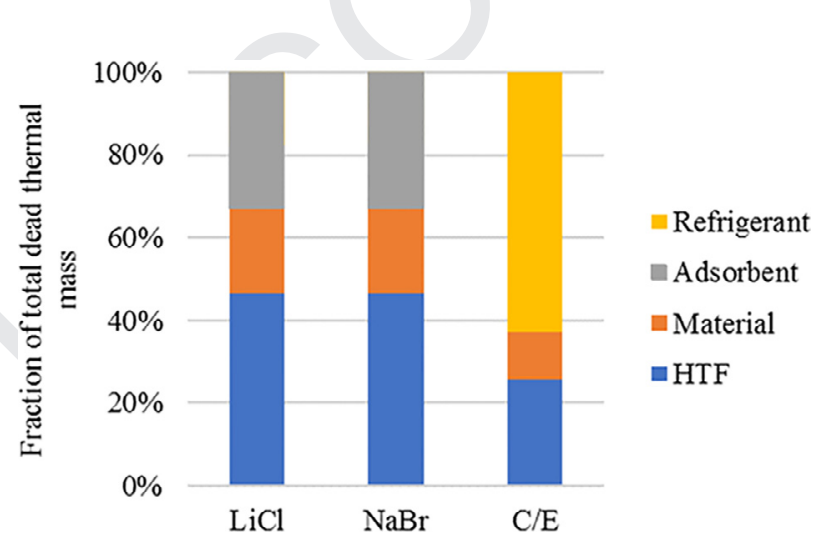

Fig. 5. Contribution of each dead thermal mass factor to DTMR for the $\mathrm{LiCl} / \mathrm{NaBr}$ RES and CCE cycles (Notes: HTF = heat transfer fluid;

$\mathrm{C} / \mathrm{E}=$ condenser/evaporator; $\mathrm{DTMR}=$ dead thermal mass ratio; $\mathrm{RES}=$ resorption cycle; $\mathrm{CCE}=$ combined condenser evaporator cycle).
COP than the SCE cycle because RES has higher $\psi$ according to the working pair property advantage in Table 7 .

Table 8 provides the analytical performance parameters of different configurations. Configurations without heat recovery $\left(\varepsilon_{1}=\varepsilon_{2}=0\right)$ and with $50 \%$ heat recovery were considered. Since heat recovery in this work only involves sensible heat recovery, a value of $50 \%$ corresponds to equilibration of the temperatures of two relevant heat exchangers before switching phases, and thus represents a upper limit for many systems.

The $\mathrm{LiCl} / \mathrm{NaBr}$ resorption cycle has the highest heating COP of 1.34 without sensible heat recovery. And this number can be improved to 1.50 when $50 \%$ sensible heat recovery is applied.

This section illustrated the use of the analytical model in the selection of working pairs and configurations, the analysis of each dead thermal mass factor effect on performance, and the influence of working condition on performance. The analytical model is also applied to study the effect of reactor design on performance for each configuration and the effect of sensible heat recovery on performance.

\section{Discussion}

\subsection{Dead thermal mass}

In this section, the influence of dead thermal mass ratio DTMR on the performance of the sorption and resorption cycles is discussed for the working pairs selected in Section 4.1. Note that the 
Table 9

Dead mass for $\mathrm{LiCl} / \mathrm{NaBr}$ reactor and condenser/evaporator $(\mathrm{C} / \mathrm{E})$ reactor.

\begin{tabular}{lllll}
\hline & & $\mathrm{LiCl}$ & $\mathrm{NaBr}$ & $\mathrm{C} / \mathrm{E}$ \\
\hline Mass of heat transfer fluid & $\mathrm{kg}$ & 15.1 & 15.1 & 7.9 \\
Mass of salt & $\mathrm{kg}$ & 20.7 & 43.8 & - \\
Mass of heat exchange material & $\mathrm{kg}$ & 60 & 60 & 27 \\
\hline
\end{tabular}

salt $\mathrm{LiCl}$ will go through three reaction steps: $3 / 2,2 / 1$, and $1 / 0$. In this work, the dead masses shown in Table 9 are assumed for each component. Based on personal experience of the authors in development of the system described in Blackman et al. (2017), these masses are considered reasonable for a system producing $10 \mathrm{~kW}$ of $50{ }^{\circ} \mathrm{C}$ hot water at an ambient of $-10^{\circ} \mathrm{C}$ and with a heat source temperature of $250^{\circ} \mathrm{C}$.

The contribution of each component of dead thermal mass to the DTMR of each reactor is calculated based on the geometry of the novel sorption heat pump reactor; the results are shown in Fig. 5. In the resorption cycle with the $\mathrm{LiCl}$ reactor and $\mathrm{NaBr}$ reactor, the dead thermal mass of HTF contributes to almost half of the DTMR; in the CCE sorption cycle, DTMR of the C/E reactor is influenced mainly by the retained refrigerant at the end of the condensation process. In the sorption cycle with separate condenser and evaporator (SCE), the DTMR of condenser and evaporator is zero.

\subsection{Model response to working temperatures}

As ambient temperature changes from the design point temperature, the temperature lift $\Delta T_{L}$ (i.e., $\left.T_{\text {cond }}-T_{\text {evap }}\right)$ is influenced more than the temperature difference $\Delta T_{D}$ (i.e., $\left.T_{\text {des }}-T_{a b s}\right)$; therefore, the DTMR of a $\mathrm{LiCl}$ reactor (HTS) remains almost the same. However, the DTMR of a $\mathrm{NaBr}$ reactor (LTS) and C/E are reduced for higher ambient temperature and increased for lower ambient temperature; therefore, the heating COP increases at temperatures higher than design point and decreases at lower temperatures. For simplicity, we assume that differential loading $\Delta Y$ is constant. In reality, this would require varying cycle time, with complex impacts on cycle power and $\Delta Y$, however such an analysis is beyond the scope of the present study. A wider temperature range is considered here to predict cycle performance under extreme cold and warmer condition. As evaluated using Eq. (20), the heating COP of the RES, CCE, and SCE cycles increases from 1.31 to $1.37,1.14$ to 1.19 , and 1.19 to 1.22 , respectively, when the ambient temperature rises from $-23^{\circ} \mathrm{C}$ to $5^{\circ} \mathrm{C}$.

\section{Conclusion}

In this study, a unified analytical model to calculate heating COP and enable rapid comparison of five different sorption cycles (ABS, ADS, SCE, CCE, and RES) was derived. This conceptual model allows direct comparison of diverse cycle types. The term DTMR was used to describe the effect of dead thermal mass on COP. The COP approach factor $\lambda$ was defined based on the dead thermal mass for ammoniate sorption with separate condenser/evaporator, combined condenser/evaporator, and resorption cycles to allow direct comparison among these cycle types.

Using available numerical and experimental results in the literature, the analytical model was verified by a classical numerical model and validated by experiment results. The model was used along with a Clapeyron diagram to select a suitable working pair for an ammoniate sorption heat pump for space heating. $\mathrm{LiCl} / \mathrm{NH}_{3}$ was selected for the RES cycle, and $\mathrm{LiCl}$ was selected for the SCE and CCE cycles.

The contribution of different dead thermal mass factors to the DTMR was studied based on the working pair selection. For salt reactors, the main contribution comes from HTF; for C/E reactors, the main contribution comes from retained refrigerant.

The model was also applied to predict the performance change under different working conditions. The heating COP of the RES, CCE, and SCE cycles increases from 1.31 to $1.37,1.14$ to 1.19 , and 1.19 to 1.22 , respectively, when the ambient temperature rises from $-23^{\circ} \mathrm{C}$ to $5^{\circ} \mathrm{C}$.

The comparison of different system configurations applying selected working pairs was carried out using the analytical model. The effect of dead thermal mass of HTF and reactor material on $\lambda$ was studied. The CCE cycle has lower $\lambda$ than the other two cycles. In a practical range of $D T M_{\text {design }}, \mathrm{LiCl} / \mathrm{NaBr}$ RES cycle and $\mathrm{LiCl}$ SCE cycles have very similar $\lambda$. Therefore, the $\mathrm{LiCl} / \mathrm{NaBr}$ RES cycle will have better COP because of the benefit of higher $\psi$.

Based on a simple analytical model calculation, for space heating applications at ambient temperature $-10^{\circ} \mathrm{C}$, heat delivery temperature of $50^{\circ} \mathrm{C}$ and up to $250^{\circ} \mathrm{C}$ driving heat source temperature, without heat recovery the highest efficiency is obtained with the $\mathrm{LiCl} / \mathrm{NaBr}$ resorption cycle, with a COP $11-15 \%$ higher than that of the competing options. With $50 \%$ recovery of sensible heat, $\mathrm{LiCl} / \mathrm{NaBr}$ still has the highest COP, $16-18 \%$ higher than that of the competing options. The $\mathrm{LiCl} / \mathrm{NaBr}$ RES cycle is shown to be a good option for the sorption cycle in space heating applications.

\section{Acknowledgments}

This work was sponsored by the US Department of Energy's Building Technologies Office under Contract No. DE-AC0500OR22725 with UT-Battelle, LLC. The authors would also like to acknowledge Mr. Antonio Bouza, Technology Manager-HVAC\&R, Water Heating, and Appliance, US Department of Energy Building Technologies Office.

The authors also gratefully acknowledge support from the National Natural Science Foundation of China (grant numbers 51306098, 51138005), the innovative Research Groups of National Natural Science Foundation of China (grant number 51521005), and the Independent Research Program from Ministry of Education of China (No. 20151080470).

\section{References}

Bao, H.S., Oliveira, R.G., Wang, R.Z., Wang, L.W., Ma, Z.W., 2011. Working pairs for resorption refrigerator. Appl. Therm. Eng. 31 (14), 3015-3021.

Blackman, C., Gluesenkamp, K., Malhotra, M., Yang, Z., 2017. Study of optimal sizing for residential sorption heat pump system. In: Proceedings of the ISHPC. Tokyo Japan.

Blackman, C., Bales, C., Thorin, E., 2017. Experimental evaluation and concept demonstration of a novel modular gas-driven sorption heat pump. In: Proceedings of the Twelfth IEA Heat Pump Conference. Rotterdam, The Netherland June 2017ISBN 978-90-9030412-0.

Cacciola, G., Restuccia, G., 1995. Reversible adsorption heat pump: a thermodynamic model. Int. J. Refrig. 18 (2), 100-106.

Douss, N, Meunier, F, 1988. Effect of operating temperature on the coefficient of performance of active-carbon methanol systems. Heat Recover. Syst. 8 (5), 383 392.

Freni, A., Dawoud, B., Bonaccorsi, L., Chmielewski, S., Frazzica, A., Calabrese, L. Restuccia, G., 2015. Characterization of zeolite-based coatings for adsorption heat pumps. SpringerBriefs in Applied Sciences and Technology, 2015. Springe ISBN 9783319093260.

Goetz, V., Spinner, B., Lepinasse, E., 1997. A solid-gas thermochemical cooling sys tem using $\mathrm{BaCl}_{2}$ and $\mathrm{NiCl}_{2}$. Energy 22 (1), 49-58.

Gluesenkamp, K., 2012. Development and analysis of micro polygeneration systems and adsorption chillers. Department of Mechanical Engineering, University of Maryland, College Park, MD, USA Doctoral dissertation.

Herold, K., Radermacher, R., Klein, S., 2016. Absorption Chillers and Heat Pumps. CRC Press, Boca Raton.

Herold, K., 1999. Performance predictions of absorption cycles using an EndoReversible model. In: Proceedings of the International Sorption Heat Pump Conference. Munich, Germany.

Lepinasse, E., Goetz, V., Crosat, G., 1994. Modelling and experimental investigation of a new type of thermochemical transformer based on the coupling of two solid-gas reactions. Chem. Eng. Process. Process Intensif. 33 (3), 125-134.
609

586 
Li, T., Wang, R., Kiplagat, J.K., 2013. A target-oriented solid-gas thermochemical sorption heat transformer for integrated energy storage and energy upgrade. AIChE J. 59 (4), 1334-1347.

Li, T.X., Wang, R.Z., Li, H., 2014. Progress in the development of solid-gas sorption refrigeration thermodynamic cycle driven by low-grade thermal energy. Prog. Energy Combust. Sci. 40, 1-58.

Meunier, F., Neveu, P., Castaing, J., 1998. Equivalent Carnot cycles for sorption refrigeration. Int. J. Refrig. 21 (6), 472-489.

Neveu, P., Castaing, J., 1993. Solid-gas chemical heat pumps: field of application and performance of the internal heat of reaction recovery process. Heat Recover. Syst. CHP 13 (3), 233-251.

Neveu, P., Castaing, J., 1996. Analyse thermodynamique des transformateurs thermochimique solide/gaz. In: Proceedings of the International Sorption Heat Pump Conference. Montreal, Canada.

Pesaran, A., Lee, H., Hwang, Y., Radermacher, R., Chun, H.H., 2016. Review article: numerical simulation of adsorption heat pumps. Energy 100, 310-320.

Pons, M., Poyelle, F., 1999. Adsorptive machines with advanced cycles for heat pumping or cooling applications. Int. J. Refrig. 22, 27-37.

Qian, S., Gluesenkamp, K., Hwang, Y., Radermacher, R., Chun, H.H., 2013. Cyclic steady state performance of adsorption chiller with low regeneration temperature zeolite. Energy 60, 517-526.
Sharma, V.K., Kumar, E.A., 2017. Thermodynamic analysis of novel multi stage multi 675 effect metal hydride based thermodynamic system for simultaneous cooling 676 heat pumping and heat transformation. Int. J. Hydrog. Energy 42, 437-447.

Sharma, V.K., Kumar, E.A., 2018. Thermodynamic simulation of hydrogen based solid sorption heat transformer. Int. J. Therm. Sci. 12574-12580.

Wang, R., Wang, L., Wu, J., 2014. Adsorption Refrigeration Technology: Theory and Application. John Wiley \& Sons, Inc.

Wongsuwan, W., Kumar, S., Neveu, P., Meunier, F., 2001. A review of chemical heat pump technology and applications. Appl. Therm. Eng. 21 (15), 1489-1519.

Xie, X., Jiang, Y., 2015. An ideal model of absorption heat pump with ideal solution circulation. J. Refrig. 36 (1), 1-12.

Xu, J., Oliveira, R.G., Wang, R.Z., 2011. Resorption system with simultaneous heat and cold production. Int. J. Refrig. 34 (5), 1262-1267.

Zebbar, D., Kherris, S., Zebbar, S., Mostefa, K., 2012. Thermodynamic optimization of an absorption heat transformer. Int. J. Refrig. 35 (5), 1393-1401.

Zhu, C., Xie, X., Jiang, Y., 2016. A multi-section vertical absorption heat exchanger for district heating systems. Int. J. Refrig. 71, 69-84. 